\title{
Pesquisa em Educação Ambiental e Questões Epistemológicas: questões levantadas no GDP
}

Eunice Trein ${ }^{1}$

Resumo: Este artigo apresenta algumas considerações sobre as discussões ocorridas no GDP "Pesquisa em Educação Ambiental e Questões Epistemológicas" durante o VI EPEA.

Palavras-chave: Educação ambiental. Questões epistemológicas. Pós-graduação.

\section{Research on Environmental Education and Epistemological Issues: Issues raised in the RDG}

\begin{abstract}
This paper builds on the discussions carried out in the "Epistemology and Environmental Education" Research Discussion Group during the VI Research Meeting on Environmental Education.
\end{abstract}

Keywords: Environmental education. Epistemology. Graduate education.

\section{Investigación en Educación Ambiental y Cuestiones Epistemológicas: cuestiones levantadas y el GDP}

Resumen: Este artículo presenta algunas consideraciones sobre las discusiones ocurridas en el GDP "Pesquisa em Educação Ambiental e Questões Epistemológicas" - "Investigación en Educación Ambiental y Cuestiones Epistemológicas” durante el VI EPEA.

Palabras clave: Educación ambiental. Cuestiones epistemológicas. Posgrado.

Este texto procura expressar algumas preocupações a partir dos trabalhos apresentados no VI Encontro de Pesquisa em Educação Ambiental (EPEA) e das ricas discussões que se seguiram, pois entendemos que podem servir como fio condutor para novas aproximações em relação às questões epistemológicas tematizadas no evento.

\footnotetext{
1 Professora Associada I da Universidade Federal Fluminense(UFF),Rio de Janeiro, Brasil, eunicetrein@ig.com.br

2 Agradeço a colaboração da professora Rosa Maria Feiteiro Cavalari no desenvolvimento das atividades e nas discussões que ocorreram no GDP.

${ }^{3}$ Para efeito da elaboração deste texto nos referimos aos trabalhos apresentados no GDP pelo seu respectivo número de inscrição.
} 
Durante a realização do Grupo de Discussão de Pesquisa "Pesquisa em Educação Ambiental e Questões Epistemológicas" nesse evento, ocorrido em setembro de $2011^{2}$, alguns questionamentos merecem ser destacados, uma vez que evidenciam a relevância do GDP. O interesse em discutir, de forma mais aprofundada, as tendências da educação ambiental no Brasil e as diferentes vertentes epistemológicas que as embasam se explicitou na presença numerosa e constante e na participação intensa ocorrida ao longo dos debates do GDP. Os textos apresentados ${ }^{3}$ tematizaram questões desafiadoras para a consolidação do campo da educação ambiental, entendido aqui na acepção, formulada por Bourdieu, de Campo Social.

O aprofundamento das discussões sobre as questões epistemológicas se deu no contexto da própria temática do evento, "A Pesquisa em Educação Ambiental e a Pós-Graduação no Brasil", gerando um diálogo sobre o papel da pósgraduação como espaço de formação dos professores e pesquisadores da área e a necessidade de consolidar referenciais teórico-metodológicos que permitem aos educadores ambientais um posicionamento teórico e político críticos perante as políticas nacionais de educação ambiental. Nesse sentido, as discussões ocorridas no GDP transbordaram para os demais momentos do VI EPEA, tanto nas mesas-redondas quanto nas conferências e apresentações de trabalhos.

Ao articularmos as questões epistemológicas com o contexto em que as pesquisas são produzidas, ficou evidente que não podemos desconsiderar que a pesquisa em EA influencia e é influenciada pelo perfil dos programas de pósgraduação e também pela política nacional de pós-graduação vigente no país, incluindo-se aí ainda um aspecto importante, que é a avaliação à qual os programas estão submetidos. Tendo em conta esse contexto e também questões mais específicas da área, sistematizadas em vários textos e mencionadas no Dossiê sobre EA da Revista em Educação, publicado em 2009 pela UFMG, iniciamos os trabalhos da primeira sessão nos referindo, mais explicitamente, às ponderações elaboradas por Clarice S. Kawasaki e Luiz Marcelo de Carvalho, organizadores do dossiê. No texto introdutório os autores destacam que as pesquisas em EA se situam na confluência entre o campo ambiental e o campo educativo e destacam a consequente característica interdisciplinar da área. Referindo-se à observação de Isabel Carvalho (2001), Luiz Marcelo de Carvalho e Clarice Kawasaki (2009, p. 144) nos lembram do argumento de que a "EA, na experiência brasileira, não nasceu no campo educativo, mas parece ser um fenômeno cuja gênese e cujo desenvolvimento estariam mais ligados aos movimentos ecológicos e ao debate ambientalista". O que L. M. Carvalho e Kawasaki pretendem nos dizer é que aquelas concepções de caráter naturalista e conservacionista apontavam uma prática política orientada no sentido de minimizar os impactos ambientais das ações humanas. Tais percepções, ainda presentes em muitas práticas, explicariam a apresentação de grande número de trabalhos em eventos científicos que se constituem em meras descrições de 
atividades sem o devido aprofundamento dos pressupostos teóricos que as ensejam. No entanto, os organizadores do dossiê sinalizam que, mais recentemente, a produção na área vem criticando as práticas descontextualizadas voltadas à promoção de medidas de proteção da natureza e ao apelo a uma ética ecológica, sem considerar a materialidade histórica em que essas práticas educativas efetivamente ocorrem.

Nesse sentido, o texto de Layrargues e Lima (0127-1), "mapeando as macrotendências político-pedagógicas da educação ambiental contemporânea no Brasil", explicita, de forma didática, a disputa pela hegemonia simbólica e objetiva de três grandes tendências nomeadas pelos autores como "conservacionista", "pragmática" e "crítica". Embora reconhecendo os limites de uma abordagem classificatória, eles concluem que elucidar essa diferenciação implica conhecimento e autoconhecimento, o que é indispensável à práxis transformadora. A nosso ver, eles pontuam no texto uma questão crucial do ponto de vista epistemológico e do ponto de vista de seu alcance político, a saber:

$[\ldots$. as forças críticas conquistaram um espaço
significativo no campo, mas essas forças são
constantemente erodidas por esse pragmatismo
dominante que tende a converter e deslocar as
intenções educativas no sentido pragmático do
mercado [...], ou seja, os objetivos econômicos são
claramente os dominantes em detrimento dos
objetivos de cidadania, da vida pública e da educação
política. (LAYRARGUES; LIMA, 0127-1).

De diferentes formas essa análise se faz presente nos demais trabalhos apresentados e discutidos no GDP. Assim, consideramos essa questão como central para um campo científico em construção, ou seja, em que medida as disputas teórico-metodológicas podem se converter em força material no âmbito da práxis em educação ambiental?

Segundo Bourdieu (1983), precisamos encontrar as formas específicas de luta no interior de cada campo. Também é necessário verificar como ocorre a tentativa do novo em ingressar na disputa e a capacidade do dominante de defender sua posição, uma vez que a defesa se faz construindo mecanismos de exclusão dos demais. Sabemos que hoje, no Brasil, critérios pragmáticos e produtivistas em favor dos objetivos econômicos regem a produção científica e a utilização do conhecimento científico. Assim, é possível compreender que o pensamento crítico, por pressupor ações mais engajadas e coletivas, muitas vezes aparece como dominante, mas, na realidade, como assinada Bourdieu, ele é somente um pensamento novo que força a entrada no campo da EA. 
Para que um campo funcione, é preciso que haja objetos de disputas e pessoas prontas para desfrutar o jogo, dotadas de hábitos que impliquem no conhecimento e no reconhecimento das leis imanentes do jogo, dos objetos de disputas, etc. (BOURDIEU, 1983, p. 89).

O pensamento hegemônico tende a se apresentar como universalmente válido e naturaliza conceitos e categorias de análise, induz a falsos consensos obliterando divergências e simulando harmonias. Nessa medida desconsidera a história da construção do conhecimento e dos sentidos a ela subjacentes. Assim, não inclui as consequências sociais de dominação que as ciências podem ter, muitas vezes irreversíveis, tanto para os seres humanos quanto para os demais elementos da natureza. Com isso não se coloca para a ciência hegemônica a possibilidade de seu uso com outro sentido que rompa com seus aspectos destrutivos e inumanos e desse modo dê lugar a outro sentido de humanidade.

Observa-se que um certo conformismo pragmático domina o espaço acadêmico ao desconsiderar a realidade material em que a própria ciência é produzida e as imposições externas que vão paulatinamente sendo internalizadas por submissão aos processos de avaliação pelos pares, muitas vezes com regras próprias e consolidadas por outros campos do saber.

Tais questões são corroboradas no texto de Pansera de Araújo e Silva (0041-1), no qual as autoras buscam identificar autores e referenciais teóricos das pesquisas em EA apresentadas nas reuniões da ANPEd e ANPEd Sul. Elas encontram similitudes entre aqueles mais citados e apontam como preocupação comum "a formação do cidadão consciente em relação às questões ambientais". Deparam-se também com uma aposta forte no papel da escola como espaço e tempo próprios para a construção de conhecimentos, valores e atitudes que possam resultar em uma vida melhor. Pansera de Araújo e Silva entendem, no entanto, que essa visão crítica, a qual parece aproximar os autores-referência das pesquisas estudadas, contém uma variedade considerável de vertentes epistemológicas. Em síntese, o resultado é que, sob a denominação de EA crítica, é possível identificar diferentes concepções de mundo e diferentes propostas de organização da sociedade.

Tanto o texto de Layrargues e Lima quanto o de Pansera de Araújo e Silva, que foram discutidos no âmbito do GDP, convergem para uma questão que merece maiores estudos empíricos: por que os autores que se filiam às teorias mais críticas e que servem de referência para muitas pesquisas em EA disputam a hegemonia no campo material e simbólico em posição de desvantagem com as tendências pragmáticas? 
Entre os sete textos apresentados no GDP, dois evidenciaram a apropriação de uma produção teórica latino-americana que ganha corpo não só em relação às questões ambientais mas também em outros campos do conhecimento. Nos textos são mencionados autores que vêm fazendo a crítica às "teorias eurocêntricas" e à "colonialidade dos saberes".

Costa (0009-3), em seu texto "Filosofia latino-americana: pressupostos para a 'libertação ambiental", expressa a intenção de dialogar com o aporte filosófico trazido pelos autores Enrique Dussel e Leopoldo Zea, que poderiam embasar uma nova leitura de nossas práticas sociais em direção a uma cidadania com caráter libertador, em que a dimensão ambiental componha outra perspectiva de desenvolvimento, baseada na escuta do "outro" como uma exigência ética. Nessa perspectiva o desafio é superar as ações teórico-práticas excludentes que marcam o modo de produção capitalista.

Também o texto de Camargo e Tonso (0169-1), "Educação ambiental crítica e 'vivir bien'(Suma Quamaña)", se ocupa em resgatar o princípio baseado nos valores próprios dos povos originários dos Andes, onde o "vivir bien" se definiria por outra perspectiva de articulação entre individuo, comunidade e natureza. Sem desconsiderar a especificidade histórica e cultural em que o conceito foi construído, os autores enfatizam a necessidade do estabelecimento de diálogos entre culturas e experiências buscando superar a compreensão de que o modelo capitalista de organização social, econômica e cultural da sociedade humana é não apenas um modelo único, de validade universal, mas também um modelo "naturalizado" como definitivo.

Nesses dois textos podemos encontrar uma dura crítica às epistemologias pragmáticas, que, focadas nos aspectos econômicos, buscam no desenvolvimento científico e tecnológico as medidas mitigadoras do processo societário hegemônico e suas consequências locais e globais. Os autores dos dois trabalhos convergem para uma perspectiva dialógica e emancipatória, nos convidando a uma interlocução com teóricos latino-americanos que buscam resgatar das tradições dos povos nativos e das experiências das lutas contrahegemônicas, travadas ao longo dos séculos na América Latina, elementos críticos e de resistência que podem contextualizar uma educação ambiental que reconheça a crise atual não apenas como uma crise econômica e ambiental mas civilizatória. Nas palavras de Dussel (2007, p. 64):

Até muito recentemente a política não tinha descoberto sua responsabilidade ecológica [...] A previsão de permanência da vida da população de cada nação na humanidade que habita o planeta Terra é primeira e essencial função da política [...] Uma humanidade extinta obviamente aniquilaria o campo político e todos seus sistemas possíveis. 
Outros trabalhos que tivemos a oportunidade de discutir no GDP, apresentados por Rebouças (0012-1), por Ribeiro e Cavassan (0080-1) e por Nunes e Freitas (0139-1), se debruçam especialmente sobre vertentes epistemológicas que contribuem para a crítica de uma modernidade baseada em uma racionalidade instrumental e positivista. Rebouças aponta os conceitos de complexidade e interdisciplinaridade como elementos férteis para a apreensão multidimensional da realidade, o que permitiria aos sujeitos sociais estabelecer o contraponto às ideias de desenvolvimento e de progresso que embasam uma sociedade marcada pelas desigualdades sociais e por um modelo de desenvolvimento insustentável.

Para Nunes e Freitas, a contribuição do pensamento de Karl Marx se fez atual na leitura crítica da sociedade capitalista e na relação sociedade-natureza que aí se estabelece. Ao criticarem a mercantilização de todas as esferas de vida, as autoras apontam o potencial de uma educação ambiental crítica que permita superar o senso comum e alcançar a "consciência filosófica" como "concreto pensado". Assim, embora reconheçam os limites da educação no processo de transformação social, elas enfatizam a relevância da educação na transformação das relações sociais e da forma capitalista de produzir e reproduzir a vida material e social.

Ainda na perspectiva da busca de rigor epistemológico, Ribeiro e Cavassan (0080-1) exploram a teoria da percepção na obra de Merlean-Ponty como importante contribuição para a fundamentação filosófica dos estudos da percepção ambiental na EA. Os autores enfatizam que uma junção entre conhecer e sentir as experiências do mundo nos conduziria a sínteses sempre abertas a novas relações. No texto encontramos uma pertinente advertência sobre a relevância do rigor teórico conceitual na medida em que as pesquisas e também as ações práticas se sustentam em concepções de mundo que definem a relação sujeito-objeto.

Konder (1992) já nos advertiu na mesma direção, que é preciso pensar a atividade humana como crítico-prática e situar claramente o papel fundamental da teoria. Para ele:

A práxis é a atividade concreta pela qual os sujeitos humanos se afirmam no mundo, modificando a realidade objetiva e, para poderem alterá-la, transformando-se a si mesmos. É a ação que, para se aprofundar de maneira mais consequente, precisa da reflexão, do autoquestionamento, da teoria; e é a teoria que remete à ação, que enfrenta o desafio de verificar seus acertos e desacertos, cotejando-os com a prática. 
Os problemas cruciais da teoria se complicam interminável e insuportavelmente quando a teoria se autonomiza demais e se distancia excessivamente da ação. (KONDER, 1992, p. 115-116).

A educação como atividade práxica requer os dois momentos indissociáveis: o teórico e o prático. Para que seja exercida de forma cada vez mais consciente, a atividade humana demanda a teoria. Por isso, concordando com Konder, entendemos que o rigor teórico é uma exigência da própria prática.

Percorrer os textos apresentados ao GDP e enunciar as principais questões debatidas teve a intenção de destacar o movimento que o campo da EA vem fazendo para adensar as bases epistemológicas que sustentam tanto a produção teórica quanto as ações práticas que envolvem a educação formal e os espaços educativos de atuação dos movimentos sociais. Embora possamos encontrar convergência nos textos citados, verificamos tensões. As discussões subjacentes, como os embates entre modernidade e pós-modernidade, as críticas ao eurocentrismo e à colonialidade de saberes, a dicotomia sujeito-objeto, são recorrentes.

Embora o EPEA seja um encontro que, de forma isolada, não pode ser tomado como representativo de tudo o que é produzido nos espaços de pesquisa e pós-graduação do Brasil, certamente convergem para esse encontro textos de autores de diferentes partes do país, ligados a muitos grupos de pesquisa em EA. Considerando estudos apresentados na ANPEd que analisaram a produção da área (GT 22 da ANPEd), encontramos similitudes com as questões debatidas no GDP.

Um aspecto que nos chama a atenção, e que ocorre em outros espaços onde a pesquisa em EA é discutida, é a pouca atenção dos autores às questões referentes especificamente à concepção de educação com a qual estão trabalhando (Tozomi Reis, 2004). O rigor conceitual é exigido mais em relação ao modo como definimos o ambiental, já que só a partir daí se estabelecem, de forma prescritiva, as características do que a EA deve ser. Parece-nos, assim, que muitas vezes educação formal ou não formal é meio para a (com)formação a uma ideia de ambiental. Também Cavalari, Santana e Carvalho já apontavam essa questão ao analisarem as concepções de educação e de educação ambiental que estavam presentes nos trabalhos apresentados no I EPEA.

Constata-se [...] a ausência de proposições mais sistematizadas e teoricamente fundamentadas sobre o processo educativo. Assim, por vezes, aquilo que é substantivado perde o seu espaço desintegrando-se no adjetivo, que qualifica, porém carece de substância, ou 
seja, do essencial. (CAVALARI; SANTANA; CARVALHO, 2006, p. 170).

Os autores concluíam no referido texto que a educação era mencionada de forma reducionista como meio para a obtenção de determinado fim. Mais uma vez constatamos a presença de uma perspectiva pragmática que reduz o potencial do fazer educativo em vez de pensá-lo na direção da formação integral dos sujeitos sociais.

Foi auspicioso o caráter dialógico que pautou a reunião do GDP, o respeito às diferentes epistemologias discutidas; no entanto, ainda não aprofundamos um aspecto que parece ser necessário. As teorias críticas, entendidas como as que se contrapõem ao atual modo de produção social de vida, possuem diferenças e potencial heurístico entre si distintos e isso precisa ser mais profundamente estudado. Parece-nos que o embate teórico-metodológico na maneira como buscamos apreender a realidade é parte das lutas contra-hegemônicas.

$\mathrm{O}$ momento histórico em que estamos vivendo, marcado pela intensa concorrência internacional, que impõe uma profunda reestruturação produtiva, tem transformado drasticamente as relações socioambientais (EAGLETON, 2005). A naturalização do modo de produção capitalista como a etapa mais avançada da história humana - e, nessa medida, talvez a definitiva - nos traz alguns alertas. Se há contradições no capitalismo entre as classes sociais e nas relações homem-natureza, mediadas pelo trabalho humano, também na produção do conhecimento esses antagonismos se explicitam.

A grande destruição das forças produtivas, que marca o momento atual e que pode ser lida no aumento da miséria, do desemprego estrutural, da destruição dos ecossistemas, valida um pensamento crítico ao sistema, uma vez que este não cumpriu com as promessas de abundância para todos com liberdade e equidade (BENOIT, 2005).

O embate teórico, nesse contexto, se faz necessário para que explicitemos o grau de radicalidade com que cada vertente epistemológica analisa e avalia os problemas atuais que afetam toda a humanidade e em que medida permitem ou não propor alternativas transformadoras da sociedade. Por isso consideramos que as questões epistemológicas devem ser entendidas à luz da matriz ontológica que as fundamenta. De que sociedade humana estamos falando? Que relações temos estabelecido com o meio natural? Que cultura daí decorre? Que processos educativos se gestam no incessante intercâmbio entre os seres humanos e a natureza e entre os seres humanos, fertilizando as transformações do mundo e a autotransformação dos sujeitos?

González Casanova (2006) nos adverte de que, embora no discurso, muitas vezes, as ciências hegemônicas e as ciências críticas pareçam semelhantes, nos embates teórico-práticos as divergências se aprofundam. 
Um exemplo é a crença no progresso e no desenvolvimento baseado na ciência e na técnica, pretensamente universais e neutras. Há certa concordância quanto à necessidade de superarmos as dualidades estabelecidas pelo pensamento cientificista, gerado na modernidade e que opõe homem-natureza, sujeito-objeto, teoria-prática. No entanto, quando o apelo a uma visão da complexidade e da historicidade da realidade se faz negando a contradição de classe e a apropriação do conhecimento científico e tecnológico em favor da maximização dos lucros, a proximidade de pensamento entre as diversas vertentes epistemológicas se esgota.

Decorrem dessa questão as visões epistêmicas que distorcem os argumentos fundamentais do pensamento crítico em direção a um uso pragmático e instrumental do conhecimento visando à superação do que é entendido como disfunção no sistema. Trata-se, então, de estabelecer mecanismos de controle e correção como estratégia de manutenção do próprio sistema capitalista.

Essa visão pragmática, já descrita no primeiro trabalho apresentado (01271), tem implicações também para a compreensão do papel que a produção do conhecimento desempenha na sociedade. Onde ele é produzido? A quem serve? Por quem é apropriado e ressignificado? É compreendido em sua função práticotransformadora ou apenas prático-conservadora?

Layrargues (2009, p. 28) em outra oportunidade já chamava a atenção para o fato de que:

Educação ambiental com compromisso social é aquela que articula a discussão da relação entre o ser humano e a natureza inserida no contexto das relações sociais. É aquela que propicia o desenvolvimento de uma consciência ecológica no educando, mas que contextualiza seu projeto político-pedagógico de modo a enfrentar também a padronização cultural, exclusão social, concentração de renda, apatia política, além da degradação da natureza. É aquela que enfrenta o desafio da complexidade, incorporando na reflexão categorias de análise, como trabalho, mercadoria e alienação. É aquela que expõe as contradições das sociedades assimétricas e desiguais.

Vemos como relevante a continuidade dos GDPs como espaço de pesquisa e sistematização histórica da produção acadêmica sobre a EA. Mas é preciso superar certa perspectiva linear, descritiva dos objetos, métodos e procedimentos da pesquisa, e explicitar sentidos e interesses a ela subjacentes. A materialidade histórica que engendra os campos do saber não pode ser ocultada, pois a ampliação do conhecimento hoje contribui para desenvolver as forças produtivas 
e também potencializa o desenvolvimento de forças destrutivas, solapando as bases materiais e sociais de manutenção da vida. Essas contradições implicam reconhecer que a produção do conhecimento é uma produção social e, portanto, carrega uma dimensão ideológica e um compromisso de classe. Explicitar isso é parte do compromisso ético-político do pensamento crítico.

Concluímos recuperando as questões sistematizadas no mesmo GDP em 2009 conforme sintetizado por Floriani (2009). No V EPEA, em que o tema central foi "a configuração do campo de pesquisa em educação ambiental", buscou-se explicitar os desafios de um campo em construção com diversos aportes teórico-metodológicos, tendo tido destaque a dimensão epistemológica. As principais questões colocadas pelo GDP à época dizem respeito ao que é considerado pressuposto nos estudos socioambientais, ou seja, que os objetos de estudo, por sua complexidade, exigem uma abordagem interdisciplinar, permitindo a aproximação entre as diversas ciências naturais e sociais. $\mathrm{O}$ autor citado nos alerta, no entanto, de que um trabalho lastreado numa perspectiva interdisciplinar pressupõe uma sólida formação disciplinar. $O$ estudo aponta ainda que no GDP o tema da transdisciplinaridade permanece controverso e carece de maiores reflexões. Também dos resultados do $\mathrm{V}$ EPEA ficam as interrogações quanto à pertinência de a educação ambiental ter uma epistemologia própria e se não deveríamos aprofundar o diálogo com a produção já consolidada no campo da educação. Pensamos que os trabalhos apresentados no VI EPEA refletem um avanço e um amadurecimento das questões propostas em anos anteriores, bem como indicam a validade da existência do GDP voltado para questões epistemológicas. A pluralidade de enfoques nos trabalhos apresentados em 2011 merece ser acompanhada e fazer parte de um diálogo que enriqueça a educação ambiental mantendo a tensão necessária à consolidação dos argumentos que nos unem e das divergências que nos identificam.

\section{Referências}

BENOIT, Hector. Reflexões sobre o esquecimento do programa marxista. In: MORAES NETO, Benedito; GALVÃO, Andreia (Org.). Marxismo e socialismo no século 21. Campinas: Xamã, 2005. p. 87-98.

BOURDIEU, Pierre. Questões de sociologia. Rio de Janeiro: Marco Zero, 1983.

CARVALHO, Isabel Cristina de Moura. Educação Ambiental e Movimentos Sociais: elementos para uma história política do campo ambiental. Educaşão: Teoria e Prática, Rio Claro, v. 9, n. 16-17, p. 46-56, 2001.

CARVALHO, Luiz Marcelo de; KAWASAKI, Clarice Sumi. Dossiê / Educação Ambiental. Tendências da pesquisa em educação ambiental. Educação em Revista, Belo Horizonte, v. 25, n. 03, p. 143-157, dez. 2009. 
CAVALARI, Rosa Maria Feiteiro; SANTANA, Luiz Carlos; CARVALHO, Luiz Marcelo de. Concepções de educação e educação ambiental nos trabalhos do I EPEA. Pesquisa em Educação Ambiental, v. 1, n. 1, p. 141-173, jul./dez. 2006.

DUSSEL, Enrique. 20 teses de politica. Buenos Aires: CLACSO; São Paulo: Expressão Popular, 2007.

EAGLETON, Terry. Depois da teoria: um olhar sobre os estudos culturais e o pósmodernismo. Rio de janeiro: Civilização Brasileira, 2005.

FLORIANI, Dimas. Educação ambiental e epistemologia: conhecimento e prática de fronteira ou uma disciplina a mais? Pesquisa em Educação Ambiental, São Carlos, v. 4, n. 2, p. 191-202, jul./dez. 2009.

GONZÁLEZ CASANOVA, Pablo. As novas ciências e as humanidades: da academia à política. São Paulo: Boitempo, 2006.

KONDER, Leandro. O futuro da filosofia da práxis: o pensamento de Marx no século XXI. Rio de Janeiro: Paz e Terra, 1992.

LAYRARGUES, Philippe Pomier. Educação ambiental com compromisso social: o desafio da superação das desigualdades. In: LOUREIRO, Carlos Frederico Bernardo; LAYRARGUES, Philippe Pomier; CASTRO, Ronaldo Souza de (Org.). Repensar a educação ambiental: um olhar crítico. São Paulo: Cortez, 2009. p. 11-31.

TOZONI-REIS, Marília Freitas de Campos. Educação ambiental: natureza, razão e história. Campinas: Autores Associados, 2004.

Artigo recebido em 20/09/2012

Artigo aprovado em 05/11/2012 